\title{
Clinical Quiz: A man with Chest Pain
}

Ahmed Kaid NA, Roslina AR

Department of Basic Medical Sciences, Kulliyyah of Medicine, International Islamic Universiti Malaysia Jalan Sultan Ahmad Shah, Bandar Indera Mahkota, 25200, Kuantan, Pahang, Malaysia

\section{History}

Mr Lee, a 54-year-old businessman was brought to the $A \& E, H T A A$ due to severe retrosternal pain. The pain was persistent, associated with dyspnoea and not relieved by rest. He had a few episodes of vomiting without blood. He admitted having mild chest discomfort and reduced effort tolerance over the last few months. He is a known case of essential hypertension and has been on haphazard follow-up for the last 5 years. He has been a chronic heavy smoker and social drinker for the past 30 years.

During examination, Mr Lee was anxious, dyspneic, restless and confused. His tongue and lips were cyanosed. His extremities were cold and clammy. The jugular pulsation was visible in the right side of his neck, $7 \mathrm{~cm}$ above the sternal angle. He had nicotine stained fingernails. His temperature was $37.5{ }^{\circ} \mathrm{C}$; pulse rate was 122 beats/min, irregular.
The blood pressure was $90 / 50 \mathrm{mmHg}$ and respiratory rate was $25 / \mathrm{min}$. His body mass index was 24 . The apex beat was in the $6^{\text {th }}$ intercostal space by the midclavicular line. There was no thrill or parasternal heave. He had a gallop rhythm without murmurs. There was mild bilateral ankle edema and bilateral basal crepitations. Funduscopy revealed grade 2 hypertensive retinopathy.

Investigations revealed abnormal lipid profile (total cholesterol, triglycerides, and LDL were high) and creatine kinase was $800 \mathrm{IU} / \mathrm{L}$ (normal < 160). ABG showed $\mathrm{pH}$ 7.35; $\mathrm{PCO}_{2} 50 \mathrm{mmHg} ; \mathrm{PO}_{2} 80 \mathrm{mmHg}$ and $\mathrm{HCO}_{3} 24 \mathrm{mmHg}$. The plain chest X-ray revealed cardiomegaly with evidence of pulmonary edema. ECG was taken immediately.

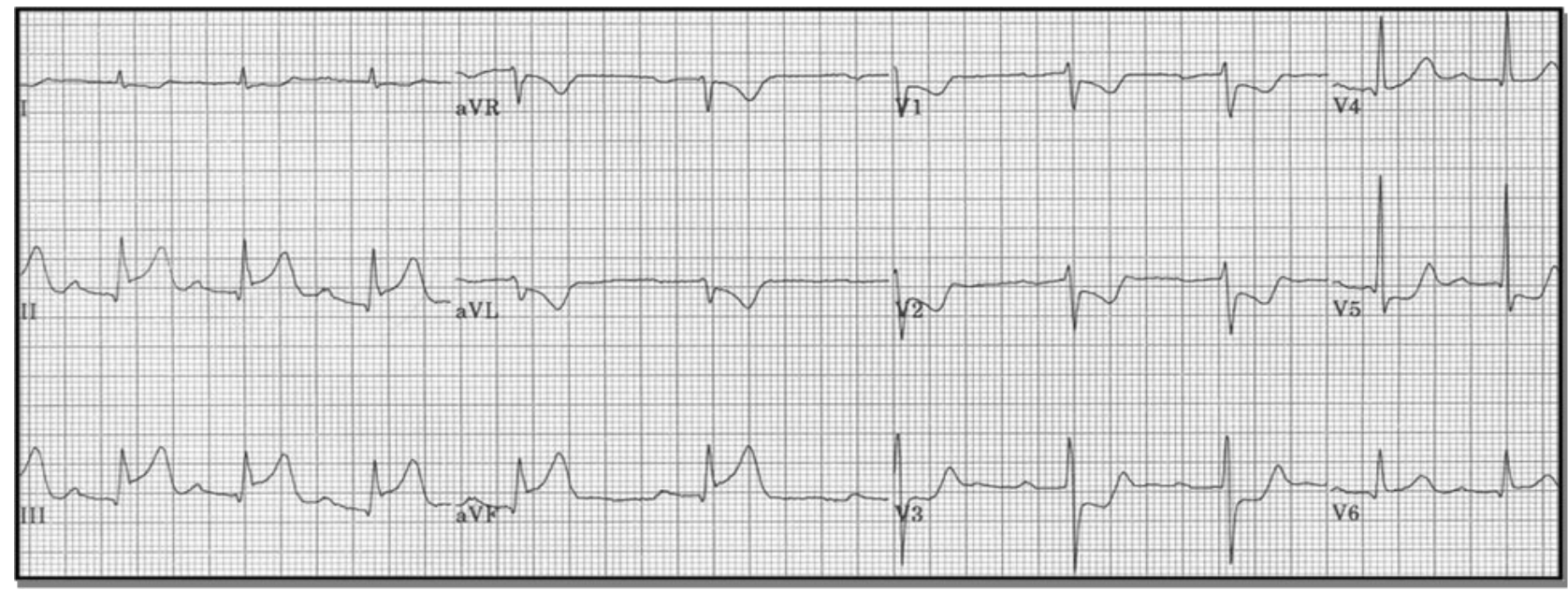

Figure 1. ECG shows elevated ST segment in LII, LIII, aVF, prolonged PR-interval and ST segment depression in $\mathrm{V} 1-3$. It represents posterior myocardial injury.

Corresponding author:

Dr Roslina Abdul Rahim

Department of Basic Medical Science

Kulliyyah of Medicine, IIUM,

Jalan Sultan Ahmad Shah,

Bandar Indera Mahkota,

25200, Kuantan, Pahang DM.

Office : $609-5704000$

Ext : 4505

Email : roslinaar@iium.edu.my
Questions:

1. What is the most likely diagnosis?
A- Acute myocardial infection
B- Angina pectoris
C- Ruptured aortic aneurysm
D- Cardiac tamponade
E- Massive pulmonary embolism

Answer: A 
2. What are the ECG findings that can support diagnosis of this case?
A-Absent of P-wave
B-Elevated ST-segment
C-Left axis deviation
D-P-mitral
E-Prolonged P-R interval

\section{Answer: $B$ and $E$}

Acute myocardial infarction $(\mathrm{MI})$ remains a leading cause of morbidity and mortality worldwide. It occurs when myocardial ischemia, exceeds a critical threshold and overwhelms myocardial cellular repair mechanisms designed to maintain normal function and homeostasis. Ischemia at this critical threshold level for an extended period results in irreversible myocardial cell damage or death. Myocardial infarction is classified by clinical scenario into various subtypes. Type 1 is a spontaneous MI related to ischemia from a plaque rupture or thrombotic occlusion. Type 2 is secondary to ischemia from a supply-and-demand mismatch. Type 3 is an MI resulting in sudden cardiac death. Type $4 \mathrm{a}$ is an $\mathrm{MI}$ associated with percutaneous coronary intervention, and $4 \mathrm{~b}$ is associated with in-stent thrombosis. Type 5 is $\mathrm{Ml}$ associated with coronary artery bypass surgery. ${ }^{1}$ The presence of $\mathrm{Q}$ waves or ST segment elevation is associated with higher early mortality and morbidity; however, the absence of these two findings does not confer better long-term reductionin mortality and/or morbidity. ${ }^{2}$

\section{REFERENCES}

1. Michael Bolooki, Arman Askari (2010): Acute Myocardial Infarction. Disease Manag Proj.

Available at http://

www.clevelandclinicmeded.com/medicalpubs/

diseasemanagement/cardiology/acutemyocardial-infarction/

2. Andreson J, Adams C, Antman E, et al: ACC/AHA 2007 guidelines for the management of patients with unstable angina/non-ST elevation myocardial infarction: A report of the American College of Cardiology/American Heart Association Task Force on Practice Guidelines. J Am Coll Cardiol 2007, 50: e1. 